\title{
EFFECT OF CONCRETE STRESS STATES ON CARBONATION DEPTH OF CONCRETE
}

\author{
Jian WANG ${ }^{1}$, Pui-Lam NG ${ }^{2} 3^{*}$, Han SU${ }^{1}$, Jiajian $\mathrm{CHEN}^{4}$, Jinsheng $\mathrm{DU}^{1}$ \\ ${ }^{1}$ School of Civil Engineering, Beijing Jiaotong University, Beijing 100044, China \\ ${ }^{2}$ Faculty of Civil Engineering, Vilnius Gediminas Technical University, Vilnius 10223, Lithuania \\ ${ }^{3}$ Department of Civil Engineering, The University of Hong Kong, Hong Kong, China \\ ${ }^{4}$ School of Transportation and Civil Engineering and Architecture, Foshan University, Foshan 528000, China
}

Received 05 January 2019; accepted 13 March 2019

\begin{abstract}
Carbonation can lead to reduction of alkalinity of concrete and initiation of steel reinforcement corrosion. In durability design of concrete structures, the carbonation depth should be duly considered. However, the concrete stress state would influence the carbonation depth, and there has been inadequate research on such effect. In this study, it is proposed to introduce a stress influence coefficient to the concrete carbonation depth model. With reference to the experimental data from eleven research studies in the literature encompassing both tensile and compressive stress states, the relationship between stress influence coefficient and concrete stress ratio is quantitatively investigated, and mathematical equations relating the stress influence coefficient with the concrete stress ratio are established. Comparative study with three typical existing groups of equations shows that the proposed equations of stress influence coefficient are more reasonable and have a higher reliability. The effects of carbonation time, mix proportions of concrete on stress influence coefficient are also analysed, and the magnitudes of the effects are found to be approximately within $\pm 10 \%$. Finally, the modified carbonation depth models are proposed and verified by the experimental data, which suggests that the proposed models are of desirable accuracy. Adoption of the proposed equations as the modified formula of stress influence coefficient in the concrete carbonation depth model for practical applications is recommended.
\end{abstract}

Keywords: carbonation depth model, concrete carbonation, concrete stress state, stress influence coefficient.

\section{Introduction}

Concrete carbonation refers to the phenomenon that carbon dioxide from the atmosphere penetrates into the concrete and reacts with the alkaline compounds (including mainly calcium hydroxide, with minor participation of calcium silicates hydrates, etc.) to form calcium carbonate and other reaction products (Kobayashi, Suzuki, \& Uno, 1994; Borges, Costa, Milestone, Lynsdale, \& Streatfield, 2010; Bary \& Sellier, 2004; Possan, Thomaz, Aleandri, Felix, \& Santos, 2017). The gradual depletion of lime due to carbonation would reduce the alkalinity of concrete. When the $\mathrm{pH}$ value in concrete is eventually decreased from close to 13 to 9 , the steel reinforcement embedded in concrete would be de-passivated and become susceptible to corrosion (Bouchaala, Payan, Garnier, \& Balayssac, 2011; Neves, Branco, \& Brito, 2013). Hence, the carbonation process would indirectly aggravate the durability problem and reduce the service life of concrete structures (Nguyen, Bary, \& Larrard, 2015; Ghantous, Poyet, L'Hostis,
Tran, \& François, 2017). In general, the factors affecting concrete carbonation can be categorised into internal and external factors (Li et al., 2018). The internal factors are related to the material aspects of the concrete mix, including water-cement ratio, cement consumption, curing conditions, concrete strength, etc. (Khunthongkeaw, Tangtermsirikul, \& Leelawat, 2006; Paul, Panda, Huang, Garg, \& Peng, 2018; Li et al., 2018). The external factors are related to the service conditions of the concrete, including relative humidity, temperature, carbon dioxide concentration, concrete stress state and so on (Wang, Lu, Y. Li, Yuan, \& Q. Li, 2017; Paul et al., 2018; Li et al., 2018). With the environment being increasingly polluted, the higher concentration of carbon dioxide in the atmosphere would aggravate concrete carbonation (Possan et al., 2017). From durability design viewpoint, in order to prevent the occurrence of de-passivation, the carbonation depth throughout the service life of structures should be less than the

*Corresponding author. E-mail: irdngpl@gmail.com 
concrete cover thickness to avoid reaching the embedded reinforcement (Chang \& Chen, 2006). To achieve rational durability design with respect to different design life and service conditions, it is of vital importance to study the carbonation depth model of concrete.

Throughout the past years, the concrete carbonation phenomenon has been widely researched (Papadakis, Vayenas, \& Fardis, 1991a, 1991b; Ishida \& Li, 2008; Ruan \& Pan, 2012; Kari, Puttonen, \& Skantz, 2014; Li, Dong, Bai, Lei, \& Du, 2017a). However, very few researchers considered the influence of concrete stress on carbonation rate and carbonation depth. Because of widespread applications of prestressed concrete structures and the effects of various loads on concrete structures during operation, it is particularly important to study the carbonation phenomenon under concrete stress (Niu, 2003; Jiang, Gu, Zhang, \& Zou, 2015; Wang et al., 2017; Wang, Su, \& Du, 2018; Tang, Wu, Zou, Yue, \& Mueller, 2018). In order to consider the role of concrete stress in carbonation depth, a stress influence coefficient was supplemented to the concrete carbonation depth model in Chinese Standard CECS 220 (2007), and for simplicity, the stress influence coefficients were set as constants for concrete under tensile and compressive stress states, respectively. Some researchers (Zhang, 2001; Tu, 2002; Liu, Lu, Lei, \& Lv, 2004; Pan, 2005; Shi, 2008; Wu, 2009; Wang, 2012; Huang, 2013) suggested that the stress influence coefficient should be expressed as a function of concrete stress, and the calculation formulas of stress influence coefficient with variable concrete stress were proposed accordingly. On the other hand, some researchers (Liu, 1997; Chen, 2007; Zhang, Sun, Chen, Guo, \& Zhao, 2007; Yang, Pan, Zhu, \& Wu, 2008; Liu, 2008a) recommended that the stress influence coefficient should be expressed as a function of concrete stress ratio.

Since concrete of different strength grades have different tensile and compressive strengths, a given concrete stress would correspond to a different ratio of the tensile or compressive strength in different strength grades of concrete. Consequently, albeit at the same concrete stress, the different tensile stress ratio or compressive stress ratio would have different effects on the carbonation rate and carbonation depth. Therefore, the laws relating the stress influence coefficient to concrete stress should be dependent on the concrete grade. In order to deduce the stress influence coefficient equations that are suitable for different concrete grades, the authors have collected experimental data from vast literature (Zhang, 2001; Zhang et al., 2007; Liu, 2008a; Shi, 2008; Wu, 2009; Zhou, 2011; Wang, 2012; Li, Du, Liu, \& Zhang, 2017b; Wang et al., 2017; Zhang, Wang, Han, \& Liu, 2017; Wang, 2018) to investigate the relationship between stress influence coefficient and concrete stress ratio, based on which mathematical equations are devised. To evaluate the reliability of the proposed equations of stress influence coefficient, they are compared with three other groups of existing equations (Liu, 1997; CECS 220, 2007; Liu 2008a). Furthermore, the effects of carbonation time, mix proportions of concrete on stress influence coefficient are also analysed. At last, the modi- fied concrete carbonation depth models are proposed, and the proposed models are verified by the experimental data from literature.

\section{Concrete carbonation depth model}

During curing and hardening of concrete, $\mathrm{Ca}(\mathrm{OH})_{2}$, or lime, is produced by cement hydration in the paste of concrete, thereby forming a strongly alkaline environment inside concrete. Normally, the $\mathrm{pH}$ value inside concrete is above 12.5. Under such $\mathrm{pH}$ value, a passivation layer (densified $\mathrm{Fe}_{3} \mathrm{O}_{4}-\gamma \mathrm{Fe}_{2} \mathrm{O}_{3}$ film) with a thickness of about $2-10 \mu \mathrm{m}$ would be formed on the surface of steel reinforcement and prevent corrosion of steel to occur (Shui et al., 2018). During the operation stage of concrete structures, $\mathrm{CO}_{2}$ in the atmosphere intrudes into concrete and reacts with the lime, resulting in a decrease of alkalinity inside the concrete. When the $\mathrm{pH}$ value drops to below 9 , the passivation film on the surface of steel reinforcement would be destroyed, i.e. de-passivation, and the corrosion of reinforcement will occur if there is the presence of sufficient oxygen and water. Generally, the damage of the passivation film is regarded as the initiating factor of reinforcement corrosion (Heiyantuduwa, Alexander, \& Mackechnie, 2006; Zhou, Gencturk, Willam, \& Attar, 2015). The entire chemical process of concrete carbonation can be expressed in Eqn (1) (Papadakis, Vayenas, \& Fardis, 1989; Zhou et al., 2015):

$$
\begin{aligned}
& \mathrm{Ca}(\mathrm{OH})_{2} \rightarrow \mathrm{Ca}^{2+}{ }_{(\mathrm{aq})}+2 \mathrm{OH}^{-}{ }_{(\mathrm{aq})} ; \\
& \mathrm{Ca}^{2+}{ }_{(\mathrm{aq})}+2 \mathrm{OH}^{-}{ }_{(\mathrm{aq})}+\mathrm{CO}_{2} \rightarrow \mathrm{CaCO}_{3}+\mathrm{H}_{2} \mathrm{O} ; \\
& 3 \mathrm{CaO} \cdot 2 \mathrm{SiO}_{2} \cdot 3 \mathrm{H}_{2} \mathrm{O}+3 \mathrm{CO}_{2} \rightarrow 3 \mathrm{CaCO}_{3} \cdot 2 \mathrm{SiO}_{2} \cdot 3 \mathrm{H}_{2} \mathrm{O}
\end{aligned}
$$

$$
\mathrm{CaO} \cdot \mathrm{SiO}_{2}+\mu \mathrm{H}_{2} \mathrm{O}+\mathrm{CO}_{2} \rightarrow \mathrm{CaCO}_{3}+\mathrm{SiO}_{2} \cdot \mu \mathrm{H}_{2} \mathrm{O} \text {.(1d) }
$$

At present, there are many models for calculating the carbonation depth of concrete, and the model can be categorised as theoretical model, semi-theoretical/semi-empirical model, and empirical model. The theoretical model (Papadakis et al., 1991a; Steffens, Dinkler, \& Ahrens, 2002; Ishida \& Li, 2008) is derived from physical principles. The parameters are well defined physical quantities and have clear meanings, but they are often difficult to be determined in practice. Hence, the application of the theoretical model is limited. The semi-theoretical/semi-empirical model (Neves et al., 2013; Hills, Gordon, Florin, \& Fennell, 2015) has a theoretical basis and is formulated in a way such that the parameters can be obtained by empirical means. With regard to the factors influencing the rate of carbonation process, a number of influence coefficients could be introduced to the semi-theoretical/semiempirical model. Usually, there is no theoretical calculation method for the influence coefficients, which can be obtained from carbonation test data or from empirical algorithms. Lastly, the empirical model (Niu, 2003; CECS 220, 2007; Paul et al., 2018) is mainly established by case classification, trend identification and statistical correlation of field measurement data or experimental results, or 
by various means of numerical optimisation. The accuracy of empirical model may vary from case to case (Paul et al., 2018).

An empirical carbonation depth model of concrete is given in Chinese Standard CECS 220 (2007), as shown in Eqn (2). In this model, the influence of concrete compressive strength, ambient temperature, relative humidity, $\mathrm{CO}_{2}$ concentration and concrete stress on the depth of concrete carbonation are considered. Eqn (2) is adopted for analysis and comparison in this paper.

$$
\begin{gathered}
x=K \sqrt{t} ; \\
K=3 K_{\mathrm{CO}_{2}} K_{k l} K_{k t} K_{k s} K_{F} T^{1 / 4} R H^{1.5}(1-R H)\left(\frac{58}{f_{c u k}}-0.76\right) ; \\
K_{\mathrm{CO}_{2}}=\sqrt{C_{0} / 0.03} ; \\
K_{F}=1.0+13.34 F^{3.3}
\end{gathered}
$$

where $x$ indicates the depth of concrete carbonation, $\mathrm{mm}$; $K_{k s}$ is the stress influence coefficient, for concrete under tensile stress, $K_{k s}=1.1$, for concrete under compressive stress, $K_{k s}=1.0 ; K_{k l}$ is the position influence coefficient, at corner positions of the concrete structure, $K_{k l}=1.4$, at non-corner positions, $K_{k l}=1.0 ; K_{k t}$ represents the influence coefficient of curing and pouring, $K_{k t}=1.2 ; K_{F}$ is the fly ash replacement coefficient, for concrete containing fly ash and with low water/binder ratio, $K_{F}=1.0 ; T$ is the ambient temperature, ${ }^{\circ} \mathrm{C} ; R H$ is the relative humidity of environment, $\% ; f_{c u k}$ is the characteristic value of concrete cube compressive strength, $\mathrm{MPa}$; $t$ is the time of concrete carbonation, a (i.e. per annum); $C_{0}$ is the concentration of $\mathrm{CO}_{2}, \% ; \mathrm{F}$ is the replacement ratio of cement by fly ash, \%.

\section{Stress influence coefficient}

In order to account for the effect of concrete stress on carbonation depth, a stress influence coefficient $K_{k s}$ is added to Eqn (2b). Because the factors in Eqn (2b) influencing the carbonation depth are independent, Eqn (2) can be rewritten as Eqn (3):

$$
x_{\sigma}=K_{k s} x_{0}
$$

$x_{0}=3 K_{\mathrm{CO}_{2}} K_{k l} K_{k t} K_{F} T^{1 / 4} R H^{1.5}(1-R H)\left(\frac{58}{f_{c u k}}-0.76\right) \sqrt{t}$,

in which $x_{\sigma}$ is the carbonation depth under concrete stress state; and $x_{0}$ is the carbonation depth under zero-stress state (i.e. the concrete carbonation is not affected by any stress).

From Eqn (3), it is noted that the stress influence coefficient can be obtained if the carbonation depth at given concrete stress state and zero-stress state are known. To conduct numerical analysis, it is assumed that $K_{k s}$ has no coupling with other factors such as carbonation time, ambient temperature, relative humidity and water/cement ratio of concrete (corresponding assumptions are also contained in vast literature, such as Liu (1997), CECS 220 (2007), Yang et al. (2008), and Liu (2008a). In other words, $K_{k s}$ is only a function of the concrete stress ratio.

\subsection{Existing experimental data}

In this paper, the experimental data from Zhang (2001), Zhang et al. (2007), Liu (2008a), Shi (2008), Wu (2009), Zhou (2011), Wang (2012), Li et al. (2017b), Wang et al. (2017), Zhang et al. (2017) and Wang (2018) are utilised to investigate the influence of concrete stress on the carbonation depth of concrete. The accelerated carbonation test was conducted by the above eleven researchers in accordance with Chinese Standard GB/T 50082 (2009). In the accelerated carbonation tests, the concentration of $\mathrm{CO}_{2}$ in the carbonation chambers was all maintained at $20 \pm 3 \%$ by controlling the $\mathrm{CO}_{2}$ inlet valve and air outlet valve to adjust the air circulation. The relative humidity was all controlled at $70 \pm 5 \%$ by moisturising and/or replacement of hygroscopic desiccants as appropriate. The temperature in carbonation chambers from Zhang (2001), Zhang et al. (2007), Wu (2009), Zhou (2011) and Zhang et al. (2017) was $20 \pm 5{ }^{\circ} \mathrm{C}$, from Shi (2008), Wang (2012), Li et al. (2017b), Wang et al. (2017) and Wang (2018) was $20 \pm 2{ }^{\circ} \mathrm{C}$, and from Liu (2008a) was $20 \pm 3{ }^{\circ} \mathrm{C}$. Therefore, it can be considered that the accelerated carbonation tests performed by the above eleven researchers had practically the same environmental conditions. The relevant sets of experimental data are summarised in Tables 1 to $11\left(f_{t}\right.$ and $f_{c}$

Table 1. Carbonation depths of specimens under different concrete stress conditions (data from Zhang, 2001)

\begin{tabular}{|c|c|c|c|c|c|c|c|c|c|c|}
\hline \multirow{2}{*}{ Specimen } & \multirow{2}{*}{$\begin{array}{c}\text { Concrete } \\
\text { stress }\end{array}$} & \multirow{2}{*}{$\begin{array}{c}\text { Concrete } \\
\text { stress ratio }\end{array}$} & \multicolumn{9}{|c|}{ Carbonation depth $(\mathrm{mm})$} \\
\cline { 5 - 13 } & & & 30 days & $K_{k s}$ & 45 days & $K_{k s}$ & 60 days & $K_{k s}$ & 90 days & $K_{k s}$ \\
\hline 1 & 0 & 0 & 25.45 & 1.000 & 29.00 & 1.000 & 31.30 & 1.000 & 36.45 & 1.000 \\
\hline 2 & $0.30 f_{t}$ & 0.30 & - & - & 29.60 & 1.021 & - & - & 37.50 & 1.029 \\
\hline 3 & $0.50 f_{t}$ & 0.50 & - & - & 30.20 & 1.041 & - & - & 39.00 & 1.070 \\
\hline 4 & $0.70 f_{t}$ & 0.70 & - & - & 31.00 & 1.069 & - & - & 40.50 & 1.111 \\
\hline 5 & $0.30 f_{c}$ & 0.30 & 23.20 & 0.912 & - & - & 29.90 & 0.955 & 34.45 & 0.945 \\
\hline 6 & $0.50 f_{c}$ & 0.50 & 22.50 & 0.884 & - & - & 26.38 & 0.843 & 31.56 & 0.866 \\
\hline 7 & $0.70 f_{c}$ & 0.70 & 19.95 & 0.784 & - & - & 25.13 & 0.803 & 29.19 & 0.801 \\
\hline
\end{tabular}

Note: $\mathrm{W} / \mathrm{C}=0.40,28$-day concrete strength: $f_{t}=2.40 \mathrm{MPa}, f_{c}=28.4 \mathrm{MPa}$. 
Table 2. Carbonation depths of specimens under different concrete stress conditions (data from Zhang et al., 2007)

\begin{tabular}{|c|c|c|c|c|c|c|c|c|}
\hline \multirow{2}{*}{ Specimen } & \multirow{2}{*}{$\begin{array}{c}\text { Concrete } \\
\text { stress }\end{array}$} & \multirow{2}{*}{$\begin{array}{c}\text { Concrete } \\
\text { stress ratio }\end{array}$} & \multicolumn{7}{|c|}{ Carbonation depth $(\mathrm{mm})$} \\
\cline { 4 - 9 } & & 14 days & $K_{k s}$ & 28 days & $K_{k s}$ & 60 days & $K_{k s}$ \\
\hline \multirow{5}{*}{ FA40II35C } & 0 & 8.50 & 1.000 & 11.50 & 1.000 & 15.20 & 1.000 \\
& $0.20 f_{t}$ & 0.20 & 9.10 & 1.071 & 12.30 & 1.070 & 16.30 & 1.072 \\
& $0.35 f_{t}$ & 0.35 & 10.00 & 1.176 & 13.40 & 1.165 & 17.10 & 1.125 \\
& $0.50 f_{t}$ & 0.50 & 11.40 & 1.341 & 14.90 & 1.296 & 18.90 & 1.243 \\
& $0.65 f_{t}$ & 0.65 & 12.80 & 1.506 & 16.10 & 1.400 & 20.30 & 1.336 \\
& $0.80 f_{t}$ & 0.80 & 14.00 & 1.647 & 17.00 & 1.478 & 22.50 & 1.480 \\
\hline
\end{tabular}

Note: $\mathrm{W} / \mathrm{C}=0.40,28$-day concrete strength: $f_{t}=2.74 \mathrm{MPa}, f_{c}=35.4 \mathrm{MPa}$.

Table 3. Carbonation depths of specimens under different concrete stress conditions (data from Shi, 2008)

\begin{tabular}{|c|c|c|c|c|}
\hline Specimen & Concrete stress & Concrete stress ratio & 28 days carbonation depth $(\mathrm{mm})$ & $K_{k s}$ \\
\hline $\mathrm{N}-0$ & 0 & 0 & 14.72 & 1.000 \\
\hline $\mathrm{T}-1$ & $0.15 f_{t}$ & 0.15 & 15.10 & 1.026 \\
\hline $\mathrm{T}-2$ & $0.30 f_{t}$ & 0.30 & 15.82 & 1.075 \\
\hline $\mathrm{T}-3$ & $0.45 f_{t}$ & 0.45 & 17.90 & 1.139 \\
\hline $\mathrm{T}-4$ & $0.60 f_{t}$ & 0.60 & 19.10 & 1.216 \\
\hline $\mathrm{T}-5$ & $0.75 f_{t}$ & 0.75 & 13.56 & 1.298 \\
\hline $\mathrm{C}-1$ & $0.15 f_{c}$ & 0.15 & 12.70 & 0.921 \\
\hline $\mathrm{C}-2$ & $0.30 f_{c}$ & 0.30 & 11.60 & 0.863 \\
\hline $\mathrm{C}-3$ & $0.45 f_{c}$ & 0.45 & 10.40 & 0.788 \\
\hline $\mathrm{C}-4$ & $0.60 f_{c}$ & 0.60 & 7.90 & 0.707 \\
\hline C-5 & $0.75 f_{c}$ & 0.75 & & 0.537 \\
\hline
\end{tabular}

Note: $\mathrm{W} / \mathrm{C}=0.40,28$-day concrete strength: $f_{t}=2.28 \mathrm{MPa}, f_{c}=27.3 \mathrm{MPa}$.

Table 4. Carbonation depths of specimens under different concrete stress conditions (data from Liu, 2008a)

\begin{tabular}{|c|c|c|c|c|c|c|c|c|}
\hline \multirow{2}{*}{ Specimen } & \multirow{2}{*}{$\begin{array}{c}\text { Concrete } \\
\text { stress }\end{array}$} & \multirow{2}{*}{$\begin{array}{l}\text { Concrete } \\
\text { stress ratio }\end{array}$} & \multicolumn{6}{|c|}{ Carbonation depth (mm) } \\
\hline & & & 7 days & $K_{k s}$ & 14 days & $K_{k s}$ & 28 days & $K_{k s}$ \\
\hline \multirow{4}{*}{ D1 } & 0 & 0 & 1.12 & 1.000 & 1.49 & 1.000 & 1.75 & 1.000 \\
\hline & $0.20 f_{c}$ & 0.20 & 1.12 & 1.000 & 1.36 & 0.913 & 1.64 & 0.937 \\
\hline & $0.40 f_{c}$ & 0.40 & 1.06 & 0.946 & 1.29 & 0.866 & 1.59 & 0.909 \\
\hline & $0.60 f_{c}$ & 0.60 & 0.90 & 0.804 & 1.08 & 0.725 & 1.35 & 0.771 \\
\hline \multirow{7}{*}{ D2 } & 0 & 0 & 2.34 & 1.000 & 3.18 & 1.000 & 4.01 & 1.000 \\
\hline & $0.20 f_{t}$ & 0.20 & 2.83 & 1.209 & 3.85 & 1.211 & 4.80 & 1.197 \\
\hline & $0.40 f_{t}$ & 0.40 & 3.22 & 1.376 & 4.08 & 1.283 & 5.02 & 1.252 \\
\hline & $0.60 f_{t}$ & 0.60 & 3.64 & 1.556 & 4.47 & 1.406 & 5.43 & 1.354 \\
\hline & $0.20 f_{c}$ & 0.20 & 2.24 & 0.957 & 3.16 & 0.994 & 4.00 & 0.998 \\
\hline & $0.40 f_{c}$ & 0.40 & 2.04 & 0.872 & 3.12 & 0.981 & 3.98 & 0.993 \\
\hline & $0.60 f_{c}$ & 0.60 & 1.84 & 0.786 & 2.51 & 0.789 & 3.23 & 0.805 \\
\hline \multirow{7}{*}{ D3 } & 0 & 0 & 4.17 & 1.000 & 6.02 & 1.000 & 8.20 & 1.000 \\
\hline & $0.20 f_{t}$ & 0.20 & - & - & - & - & 9.32 & 1.137 \\
\hline & $0.40 f_{t}$ & 0.40 & 5.74 & 1.376 & 6.96 & 1.156 & 9.97 & 1.216 \\
\hline & $0.60 f_{t}$ & 0.60 & - & - & - & - & 10.61 & 1.294 \\
\hline & $0.20 f_{c}$ & 0.20 & - & - & - & - & 6.88 & 0.839 \\
\hline & $0.40 f_{c}$ & 0.40 & 3.90 & 0.935 & 5.76 & 0.957 & 6.57 & 0.801 \\
\hline & $0.60 f_{c}$ & 0.60 & - & - & - & - & 6.11 & 0.745 \\
\hline
\end{tabular}

Note: 1 . Specimen D1: W/C $=0.44,28$-day concrete strength: $f_{t}=2.01 \mathrm{MPa}, f_{c}=24.1 \mathrm{MPa}$.

2. Specimen D2: W/C $=0.42,28$-day concrete strength: $f_{t}=2.43 \mathrm{MPa}, f_{c}=29.2 \mathrm{MPa}$.

3. Specimen D3: W/C $=0.40,28$-day concrete strength: $f_{t}=2.55 \mathrm{MPa}, f_{c}=30.6 \mathrm{MPa}$. 
Table 5. Carbonation depths of specimens under different concrete stress conditions (data from Wu, 2009)

\begin{tabular}{|c|c|c|c|c|}
\hline Specimen & Concrete stress & Concrete stress ratio & 28 days carbonation depth $(\mathrm{mm})$ & $K_{k s}$ \\
\hline 1 & 0 & 0 & 6.22 & 1.000 \\
\hline 2 & $0.30 f_{t}$ & 0.30 & 6.89 & 1.108 \\
\hline 3 & $0.50 f_{t}$ & 0.50 & 7.28 & 1.170 \\
\hline 4 & $0.70 f_{t}$ & 0.70 & 7.93 & 1.275 \\
\hline
\end{tabular}

Note: $\mathrm{W} / \mathrm{C}=0.37,28$-day concrete strength: $f_{t}=2.65 \mathrm{MPa}, f_{c}=32.4 \mathrm{MPa}$.

Table 6. Carbonation depths of specimens under different concrete stress conditions (data from Zhou, 2011)

\begin{tabular}{|c|c|c|c|c|c|c|c|c|}
\hline \multirow{2}{*}{ Specimen } & \multirow{2}{*}{ Concrete stress } & \multirow{2}{*}{$\begin{array}{c}\text { Concrete stress } \\
\text { ratio }\end{array}$} & \multicolumn{5}{|c|}{ Carbonation depth $(\mathrm{mm})$} \\
\cline { 5 - 11 } & & & 14 days & $K_{k s}$ & 21 days & $K_{k s}$ & 28 days & $K_{k s}$ \\
\hline 1 & 0 & 0 & 8.10 & 1.000 & 9.78 & 1.000 & 10.84 & 1.000 \\
\hline 2 & $0.30 f_{t}$ & 0.30 & 9.43 & 1.164 & 10.45 & 1.069 & 11.19 & 1.032 \\
\hline 3 & $0.60 f_{t}$ & 0.60 & 12.67 & 1.564 & 14.69 & 1.502 & 16.68 & 1.539 \\
\hline
\end{tabular}

Note: $\mathrm{W} / \mathrm{C}=0.60,28$-day concrete strength: $f_{t}=1.67 \mathrm{MPa}, f_{c}=20.0 \mathrm{MPa}$.

Table 7. Carbonation depths of specimens under different concrete stress conditions (data from Wang, 2012)

\begin{tabular}{|c|c|c|c|c|c|c|c|c|}
\hline \multirow{2}{*}{ Specimen } & \multirow{2}{*}{ Concrete stress } & \multirow{2}{*}{$\begin{array}{c}\text { Concrete stress } \\
\text { ratio }\end{array}$} & \multicolumn{6}{|c|}{ Carbonation depth (mm) } \\
\hline & & & 7 days & $K_{k s}$ & 28 days & $K_{k s}$ & 56 days & $K_{k s}$ \\
\hline $\mathrm{Z}-0$ & 0 & 0 & 2.71 & 1.000 & 5.41 & 1.000 & 7.28 & 1.000 \\
\hline \multirow{2}{*}{$\mathrm{Z}-1$} & $0.30 f_{t}$ & 0.30 & 2.87 & 1.059 & 6.07 & 1.122 & 8.75 & 1.202 \\
\hline & $0.20 f_{c}$ & 0.20 & 2.35 & 0.867 & 5.14 & 0.950 & 7.12 & 0.978 \\
\hline \multirow{2}{*}{$\mathrm{Z}-2$} & $0.50 f_{t}$ & 0.50 & 3.12 & 1.151 & 6.48 & 1.198 & 9.14 & 1.255 \\
\hline & $0.35 f_{c}$ & 0.35 & 2.21 & 0.815 & 4.39 & 0.811 & 6.52 & 0.896 \\
\hline \multirow{2}{*}{ Z-3 } & $0.70 f_{t}$ & 0.70 & 3.42 & 1.262 & 7.14 & 1.320 & 10.09 & 1.386 \\
\hline & $0.50 f_{c}$ & 0.50 & 1.92 & 0.708 & 3.64 & 0.673 & 5.37 & 0.738 \\
\hline $\mathrm{P}-0$ & 0 & 0 & 1.57 & 1.000 & 3.65 & 1.000 & 5.28 & 1.000 \\
\hline \multirow{2}{*}{$\mathrm{P}-1$} & $0.30 f_{t}$ & 0.30 & 1.97 & 1.255 & 4.38 & 1.200 & 6.14 & 1.163 \\
\hline & $0.20 f_{c}$ & 0.20 & 1.49 & 0.949 & 3.37 & 0.923 & 5.12 & 0.970 \\
\hline \multirow{2}{*}{ P-2 } & $0.50 f_{t}$ & 0.50 & 2.17 & 1.382 & 4.56 & 1.249 & 6.39 & 1.210 \\
\hline & $0.35 f_{c}$ & 0.35 & 1.34 & 0.854 & 3.21 & 0.879 & 4.39 & 0.831 \\
\hline \multirow{2}{*}{ P-3 } & $0.70 f_{t}$ & 0.70 & 2.34 & 1.490 & 5.07 & 1.389 & 7.05 & 1.335 \\
\hline & $0.50 f_{c}$ & 0.50 & 1.27 & 0.809 & 2.48 & 0.679 & 3.71 & 0.703 \\
\hline
\end{tabular}

Note: 1 . Specimens Z-0-Z-3: W/C $=0.30$, 28-day concrete strength: $f_{t}=3.00 \mathrm{MPa}, f_{c}=36.4 \mathrm{MPa}$.

2. Specimens $\mathrm{P}-0-\mathrm{P}-3$ : $\mathrm{W} / \mathrm{C}=0.30,28$-day concrete strength: $f_{t}=2.80 \mathrm{MPa}, f_{c}=33.8 \mathrm{MPa}$.

Table 8. Carbonation depths of specimens under different concrete stress conditions (data from Li et al., 2017b)

\begin{tabular}{|c|c|c|c|c|c|c|c|c|}
\hline \multirow{2}{*}{ Specimen } & \multirow{2}{*}{ Concrete stress } & \multirow{2}{*}{$\begin{array}{l}\text { Concrete stress } \\
\text { ratio }\end{array}$} & \multicolumn{6}{|c|}{ Carbonation depth (mm) } \\
\hline & & & 7 days & $K_{k s}$ & 14 days & $K_{k s}$ & 28 days & $K_{k s}$ \\
\hline \multirow{5}{*}{$(20,10)$} & 0 & 0 & 7.20 & 1.000 & 12.40 & 1.000 & 19.20 & 1.000 \\
\hline & $0.20 f_{t}$ & 0.20 & 8.80 & 1.222 & 14.50 & 1.169 & 20.90 & 1.089 \\
\hline & $0.40 f_{t}$ & 0.40 & 9.10 & 1.264 & 17.00 & 1.371 & 24.50 & 1.276 \\
\hline & $0.20 f_{c}$ & 0.20 & 6.10 & 0.847 & 11.10 & 0.895 & 16.50 & 0.859 \\
\hline & $0.40 f_{c}$ & 0.40 & 5.80 & 0.806 & 10.90 & 0.879 & 15.60 & 0.813 \\
\hline
\end{tabular}

Note: $\mathrm{W} / \mathrm{C}=0.43,28$-day concrete strength: $f_{t}=2.13 \mathrm{MPa}, f_{c}=25.5 \mathrm{MPa}$. 
Table 9. Carbonation depths of specimens under different concrete stress conditions (data from Zhang et al., 2017)

\begin{tabular}{|c|c|c|c|c|}
\hline Specimen & Concrete stress & Concrete stress ratio & 28 days carbonation depth $(\mathrm{mm})$ & $K_{k s}$ \\
\hline 1 & 0 & 0 & 4.50 & 1.000 \\
\hline 2 & $0.30 f_{t}$ & 0.30 & 4.80 & 1.067 \\
\hline 3 & $0.40 f_{t}$ & 0.40 & 5.20 & 1.156 \\
\hline 4 & $0.50 f_{t}$ & 0.50 & 5.70 & 1.267 \\
\hline 5 & $0.30 f_{c}$ & 0.30 & 4.20 & 0.933 \\
\hline 6 & $0.40 f_{c}$ & 0.40 & 3.50 & 0.778 \\
\hline 7 & $0.50 f_{c}$ & 0.50 & 3.40 & 0.756 \\
\hline
\end{tabular}

Note: $\mathrm{W} / \mathrm{C}=0.35,28$-day concrete strength: $f_{t}=1.96 \mathrm{MPa}, f_{c}=25.3 \mathrm{MPa}$.

Table 10. Carbonation depths of specimens under different concrete stress conditions (data from Wang et al., 2017)

\begin{tabular}{|c|c|c|c|c|c|c|}
\hline \multirow{2}{*}{ Specimen } & \multirow{2}{*}{ Concrete stress } & Concrete stress ratio & \multicolumn{4}{|c|}{ Carbonation depth $(\mathrm{mm})$} \\
\cline { 3 - 7 } & & & 7 days & $K_{k s}$ & 14 days & $K_{k s}$ \\
\hline \multirow{3}{*}{ FA0 } & 0 & 0 & 5.70 & 1.000 & 9.20 & 1.000 \\
\cline { 2 - 7 } & $0.30 f_{t}$ & 0.30 & 6.50 & 1.140 & 10.40 & 1.130 \\
\cline { 2 - 7 } & $0.50 f_{t}$ & 0.50 & 8.10 & 1.421 & 12.30 & 1.337 \\
\cline { 2 - 7 } & $0.70 f_{t}$ & 0.70 & 9.90 & 1.737 & 15.60 & 1.696 \\
\hline
\end{tabular}

Note: $\mathrm{W} / \mathrm{C}=0.56,28$-day concrete strength: $f_{t}=2.04 \mathrm{MPa}, f_{c}=27.4 \mathrm{MPa}$.

Table 11. Carbonation depths of specimens under different concrete stress conditions (data from Wang, 2018)

\begin{tabular}{|c|c|c|c|c|c|c|}
\hline \multirow{2}{*}{ Specimen } & \multirow{2}{*}{ Concrete stress } & \multirow{2}{*}{ Concrete stress ratio } & \multicolumn{4}{|c|}{ Carbonation depth $(\mathrm{mm})$} \\
\cline { 4 - 7 } & & & 14 days & $K_{k s}$ & 28 days & $K_{k s}$ \\
\hline A0 & 0 & 0 & 13.91 & 1.000 & 19.59 & 1.000 \\
\hline A1 & $0.10 f_{t}$ & 0.10 & 14.08 & 1.012 & 19.89 & 1.015 \\
\hline A2 & $0.20 f_{t}$ & 0.20 & 14.24 & 1.024 & 20.15 & 1.029 \\
\hline A3 & $0.30 f_{t}$ & 0.30 & 14.58 & 1.048 & 20.74 & 1.059 \\
\hline A4 & $0.40 f_{t}$ & 0.40 & 14.89 & 1.070 & 21.21 & 1.083 \\
\hline
\end{tabular}

Note: $\mathrm{W} / \mathrm{C}=0.35,28$-day concrete strength: $f_{t}=2.30 \mathrm{MPa}, f_{c}=28.1 \mathrm{MPa}$.

are respectively the concrete tensile strength and concrete compressive strength; $K_{k s}$ is calculated from Eqn (3)). These data are utilised to study the relationship between stress influence coefficient and concrete stress ratio (including concrete tensile stress ratio $\delta_{T}=\sigma_{t} / f_{t}$ and concrete compressive stress ratio $\delta_{C}=\sigma_{c} / f_{c}$; where $\sigma_{t}$ and $\sigma_{c}$ are respectively the concrete tensile stress and compressive stress).

\subsection{Establishing equations for stress influence coefficient}

The relationships between $K_{k s}$ and concrete tensile and compressive stress ratios are plotted in Figures 1 and 2, respectively. It can be seen from the figures that the relationships between the stress influence coefficient and the concrete tensile stress ratio and the concrete compressive stress ratio can be approximately described by quadratic function. The stress influence coefficient increases with increasing concrete tensile stress ratio, while it decreases with increasing concrete compressive stress ratio. The main reason for this phenomenon is that under increasing concrete tensile stress, the increase in porosity of concrete due to tensile deformation, as well as the widening of existing micro-cracks and the initiation and propagation of new micro-cracks would augment the $\mathrm{CO}_{2}$ diffusion channels and increase carbonation rate, and lead to increase in concrete carbonation depth (Jiang et al., 2015; Wang et al., 2017). On the contrary, under the action of compressive stress, the decrease in porosity of concrete due to compressive deformation, as well as the partial or full closure of existing micro-cracks would reduce the $\mathrm{CO}_{2}$ diffusion channels and decrease carbonation rate, and lead to decrease in concrete carbonation depth. The above phenomenon has been researched by Wang et al. (2017), Li et al. (2018) and Wang et al. (2018). At higher compressive stress $\left(\sigma_{c}>0.3 f_{c}\right)$, new micro-cracks would form and the concrete would exhibit inelastic deforma- 


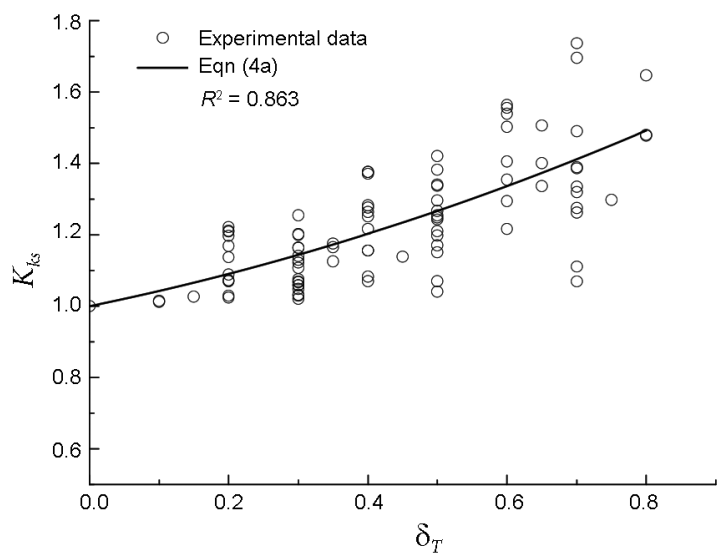

Figure 1. Relationship between $K_{k s}$ and concrete tensile stress ratio

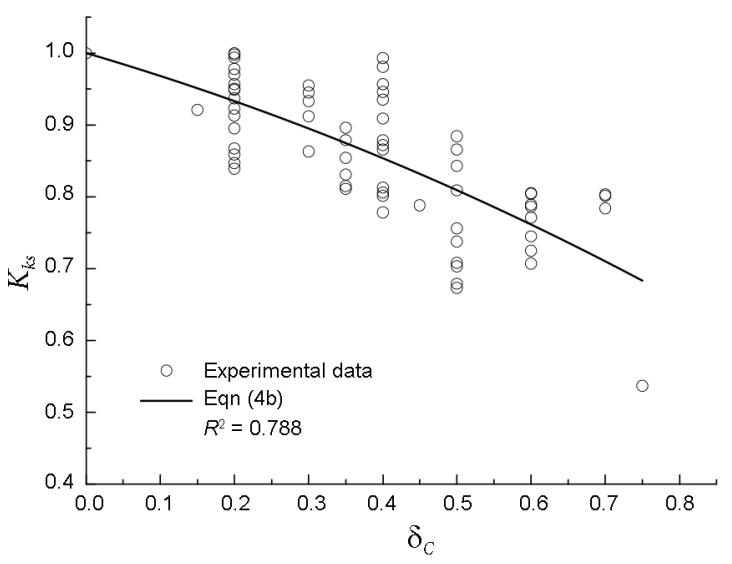

Figure 2. Relationship between $K_{k s}$ and concrete compressive stress ratio

tions (Jin, Zhang, Du, \& Li, 2015; Xu \& Li, 2017; Wang et al., 2019). Nevertheless, if the increase in volume due to formation of new micro-cracks is less than the decrease in volume of concrete pores, there would be overall reduction of $\mathrm{CO}_{2}$ diffusion channels (Wang et al., 2018), and the carbonation depth would decrease.

The relationship between $K_{k s}$ and concrete tensile and compressive stress ratios can be mathematically established by means of regression analysis, as given by Eqn (4a) (coefficient of determination $R^{2}=0.863$ ) and Eqn (4b) (coefficient of determination $R^{2}=0.788$ ), respectively. In Eqn (4a), the value of $\delta_{T}$ is limited to 1.0. Considering that the long-term compressive strength of concrete structures under sustained load normally would not exceed $0.80 f_{c}$, in Eqn $(4 \mathrm{~b}), \delta_{C}$ is limited to be not greater than 0.8 . In practical circumstances, $\delta_{T}$ and $\delta_{C}$ are usually limited to 0.4 and rarely exceed 0.5 . Hence, in general cases, Eqn (4b) can be applied.

Under tension:

$K_{k s}=1.00+0.40 \delta_{T}+0.27 \delta_{T}^{2}, \quad\left(0 \leq \delta_{T} \leq 1.0\right)$.

Under compression:

$K_{k s}=1.00-0.30 \delta_{C}-0.16 \delta_{C}^{2}, \quad\left(0 \leq \delta_{C} \leq 0.8\right)$.

\section{Validation of the proposed equations}

To validate and evaluate the proposed equations, Eqn (4a) and Eqn (4b) are compared with the experimental data reported by Liu et al. (2004), Liu (2008b), Zheng and Huang (2013), and Xue (2016). Moreover, comparative study with three typical existing groups of equations (Liu, 1997; CECS 220, 2007; Liu, 2008a) is conducted, as detailed in the following.

The first group of equations, Eqn (5a) and Eqn (5b), were proposed by Liu (1997):

$$
\begin{aligned}
& K_{k s}=1-0.0929 \delta_{T}+0.6429 \delta_{T}^{2} ; \\
& K_{k s}=1-1.275 \delta_{C}+1.916 \delta_{C}^{2} .
\end{aligned}
$$

The second group of equations, Eqn (6a) and Eqn (6b), were recommended in CECS 220 (2007):

$$
\begin{aligned}
& K_{k s}=1.1 \text { (under tension); } \\
& K_{k s}=1.0 \text { (under compression). }
\end{aligned}
$$

The last group of equations, Eqn (7a) and Eqn (7b), were proposed by Liu (2008a):

$$
\begin{aligned}
& K_{k s}=1.01+0.95 \delta_{T}-0.5 \delta_{T}^{2} ; \\
& K_{k s}=0.9953+0.1767 \delta_{C}-0.8333 \delta_{C}^{2} .
\end{aligned}
$$

Regarding the reference experimental data for validation, the specimens tested by Liu (2008b) were divided into three categories, which included tensile specimens, compressive specimens, and zero-stress specimens. The specimens had a size of $100 \times 100 \times 400 \mathrm{~mm}$. Three load levels corresponding to $0.29,0.47$ and 0.67 times the tensile strength of members were applied to the tensile specimens, and two load levels corresponding to 0.27 and 0.44 times the compressive strength of members were applied to the compressive specimens. During testing of specimens in the accelerated carbonation chambers, the temperature was $20 \pm 5{ }^{\circ} \mathrm{C}$, the relative humidity was $70 \pm 5 \%$ and the concentration of $\mathrm{CO}_{2}$ was $20 \pm 3 \%$. Carbonation depths at 28 days were determined for tensile and compressive specimens, and carbonation depths at 7 days, 14 days, 21 days and 28 days were tested for zero-stress specimens. The stress influence coefficient values obtained from the relevant experimental data are plotted in Figures 3 and 4.

Liu et al. (2004) studied the effect of concrete stress on carbonation depth. In the test, tensile specimens, compressive specimens, and zero-stress specimens were designed, and the size of the specimens was $100 \times 100 \times 400 \mathrm{~mm}$. During the loading test, three load levels corresponding to $0.3,0.5$ and 0.7 times the tensile or compressive strength of specimens were applied. The compressive specimens and zero-stress specimens were placed in the accelerated carbonation chambers for 30 days, 60 days and 90 days of duration, and the tensile specimens were placed in the accelerated carbonation chambers for 45 days and 90 days of duration. In the accelerated carbonation chambers, the temperature was $20 \pm 5{ }^{\circ} \mathrm{C}$, the relative humidity was $70 \pm 5 \%$ and the concentration of $\mathrm{CO}_{2}$ was $20 \pm 3 \%$. The 
experimental data from the compressive specimens and zero-stress specimens were adopted to validate Eqn (4). The stress influence coefficient values obtained from the relevant experimental data are plotted in Figure 4.

The specimens tested by Zheng and Huang (2013) included tensile specimens and zero-stress specimens. For tensile specimens, the size was $70.7 \times 70.7 \times 212 \mathrm{~mm}$, three load levels corresponding to $0.2,0.4$ and 0.6 times the tensile strength of members were applied. The tensile specimens were placed in the accelerated carbonation chambers for 7 days, 14 days and 28 days of duration before determining the carbonation depth. For zero-stress specimens, the size was $100 \times 100 \times 400 \mathrm{~mm}$. The specimens were placed in the accelerated carbonation chambers for 7 days, 14 days, 28 days, 42 days and 56 days of duration, and the carbonation depths were determined. In the accelerated carbonation chambers, the temperature, relative humidity and concentration of $\mathrm{CO}_{2}$ were controlled at $20 \pm 2{ }^{\circ} \mathrm{C}$, $70 \pm 5 \%$ and $20 \pm 3 \%$, respectively. The stress influence coefficient obtained from experimental data of tensile specimens with $\delta_{T}=0.2$ and 0.4 are plotted in Figure 3.

The concrete specimens tested by Xue (2016) had a size of $100 \times 100 \times 400 \mathrm{~mm}$ and were divided into three categories, which included tensile specimens, compressive specimens and zero-stress specimens. During the loading test, four load levels corresponding to $0.2,0.4,0.6$ and 0.8 times the tensile or compressive strength of members were applied. All concrete specimens were placed in the accelerated carbonation chambers for 3 days, 7 days, 14 days and 28 days of duration, and the carbonation depths were determined. The temperature, relative humidity and concentration of $\mathrm{CO}_{2}$ were respectively controlled at $20 \pm 2{ }^{\circ} \mathrm{C}$, $70 \pm 5 \%$ and $20 \pm 3 \%$ in the accelerated carbonation chambers. The stress influence coefficient values obtained from the relevant experimental data are plotted in Figures 3 and 4.

In Figures 3 and 4, the computed results from Eqns (4) to (7) are also presented in the form of curves. It can be seen that the proposed equations (Eqn (4a) and Eqn (4b)) and the experimental data are in good agreement, which is significantly better than the other equations. The maximum prediction errors of Eqn (4a) and Eqn (4b) are respectively $11.2 \%$ and $13.9 \%$, which are considered rea-

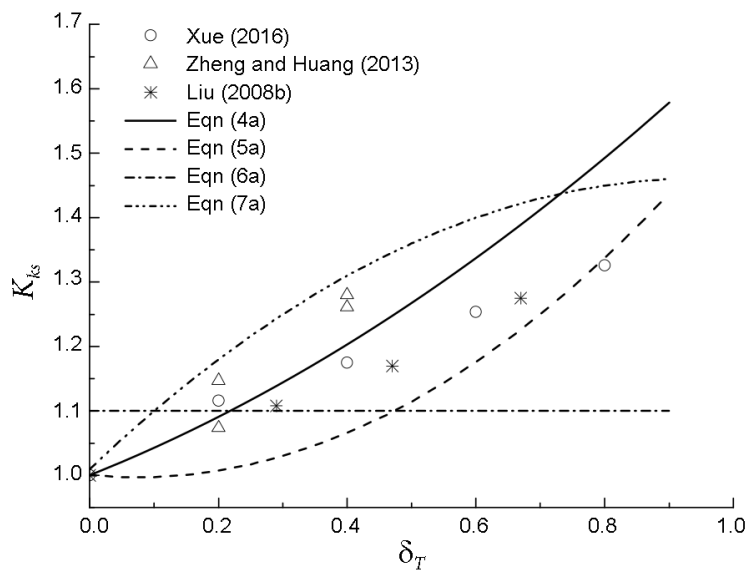

Figure 3. Comparison of computed results of $K_{k s}$ and experimental data under tensile stress

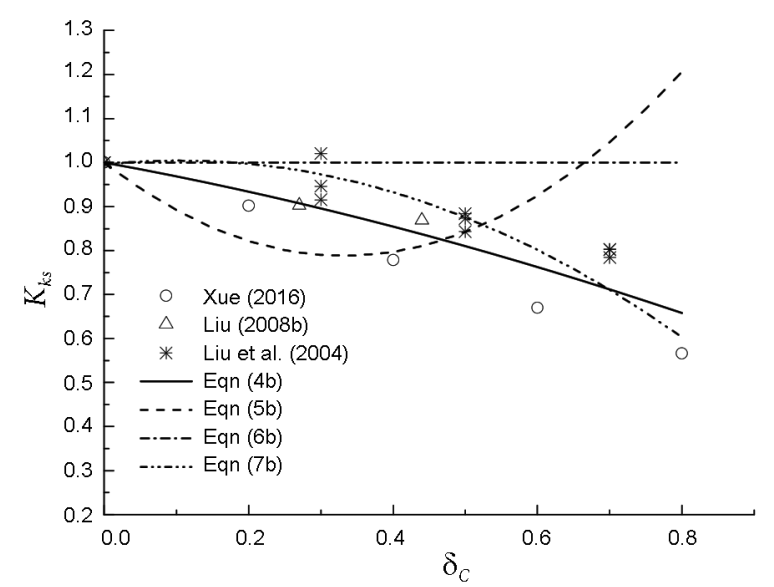

Figure 4. Comparison of computed results of $K_{k s}$ and experimental data under compressive stress

sonably accurate. In Figures 3 and 4, it can be seen that the computed results from Eqn (6a) and Eqn (6b) deviate largely from the experimental data when the tensile or compressive stress ratio is high, because CECS 220 (2007) recommends constant values of $K_{k s}$ that does not cater for the effects of concrete stress magnitude. It is advocated that the proposed Eqn (4a) and Eqn (4b) can be adopted as the modified formula for stress influence coefficient in the concrete carbonation depth model.

\section{Influence of carbonation time on stress influence coefficient}

In this section, the influence of carbonation time on the stress influence coefficient is inspected. Reference is made to the experimental data listed in Table 1 to 11 , among which Tables 1, 2, 4, 6-8, 10 and 11 reported the carbonation depth at different carbonation time. Along each row of the tables (where the environmental conditions and mix design remain constant), the arithmetic mean of the stress influence coefficient values is computed. Then the relative deviation between each stress influence coefficient value and the arithmetic mean is evaluated as per Eqn (8), and the maximum relative deviation is obtained as the relative deviation having the largest magnitude:

$$
\Delta=\left(K_{k s}^{t}-K_{k s}^{m}\right) / K_{k s}^{m} \times 100 \%,
$$

where $\Delta$ is the relative deviation; $K_{k s}^{t}$ is the stress influence coefficient value calculated from experimental data; and $K_{k s}^{m}$ is the arithmetic mean of $K_{k s}^{t}$.

The maximum relative deviation is plotted against the concrete stress ratio in Figures 5 and 6 to reveal the possible influence of carbonation time. It can be found from the figures that within the range of carbonation time studied, the carbonation time has little effect on the stress influence coefficient under both tensile and compressive stresses of concrete, and the maximum relative deviations are all approximately within $\pm 10 \%$. Therefore, the omission of carbonation time in the equations of stress influence coefficient is justifiable from practical viewpoint. 


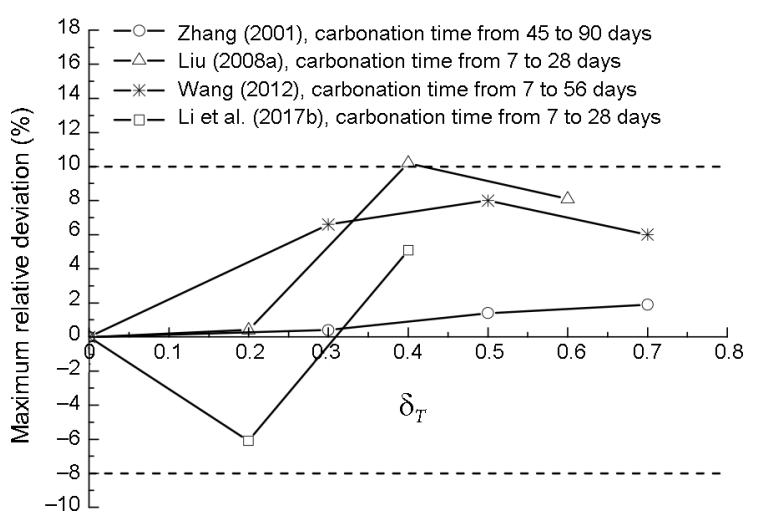

(a)

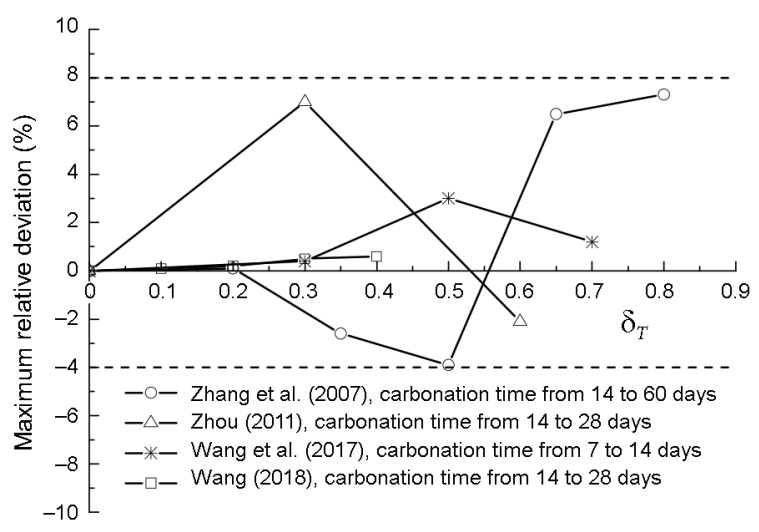

(b)

Figure 5. Influence of carbonation time on stress influence coefficient under tensile stress

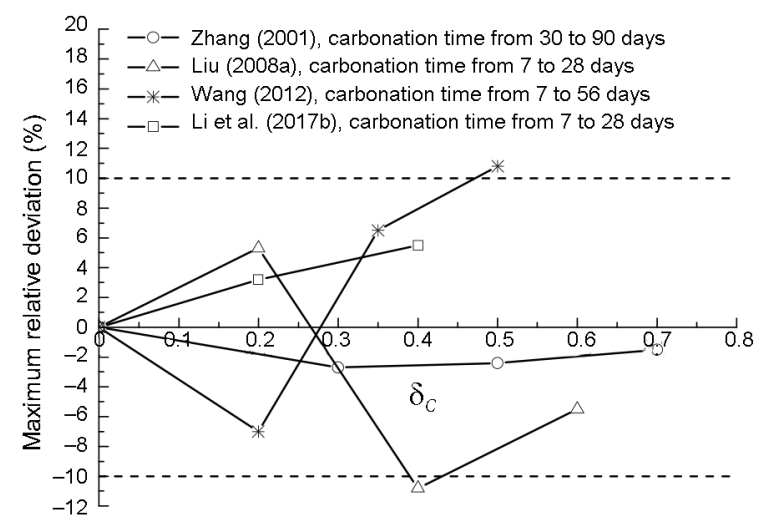

Figure 6. Influence of carbonation time on stress influence coefficient under compressive stress

\section{Influence of mix proportions of concrete on stress influence coefficient}

A number of researchers have pointed out that the mix proportions of concrete could affect the carbonation depth (Khunthongkeaw et al., 2006; Zhang et al., 2007; Wang et al., 2017; Li et al., 2018), however, little research has been done on the effect of mix proportions of concrete on the stress influence coefficient. Wang et al. (2018) reported that the magnitude of such effect is approximately within $\pm 10 \%$. In this section, the influence of concrete mix proportions on the stress influence coefficient is inspected. Reference is made to the experimental data listed in Tables 1 to 11, among which Tables 2 to 11 contain data for concrete with different mix proportions at carbonation time of 14 days and/or 28 days. Under the same concrete stress ratio, the arithmetic mean of the stress influence coefficient values from different researchers (to reflect different mix proportions) is determined with respect to carbonation time of 14 days and 28 days. Then the relative deviation between each stress influence coefficient value and the arithmetic mean is evaluated as per Eqn (8), and the maximum relative deviation is obtained as the relative deviation having the largest magnitude.

The maximum relative deviation is plotted against the concrete stress ratio in Figures 7 and 8 to reveal the possible influence of mix proportions of concrete. It can be found from the figures that within the range of mix proportions studied, the mix proportions have little effect on the stress influence coefficient under both tensile and compressive stresses of concrete, and the maximum relative deviations are all approximately within $\pm 10 \%$, which is consistent with the results of Wang et al. (2018). Therefore, the omission of concrete mix proportions in the equations of stress influence coefficient is justifiable from practical viewpoint.

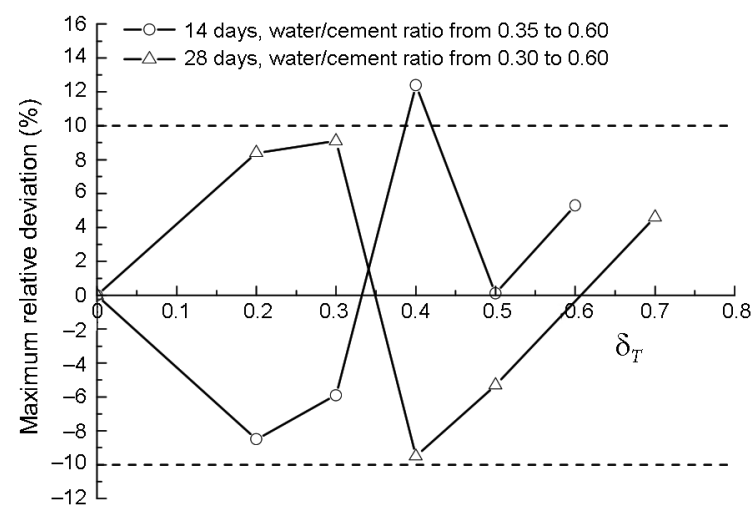

Figure 7. Influence of mix proportions of concrete on stress influence coefficient under tensile stress

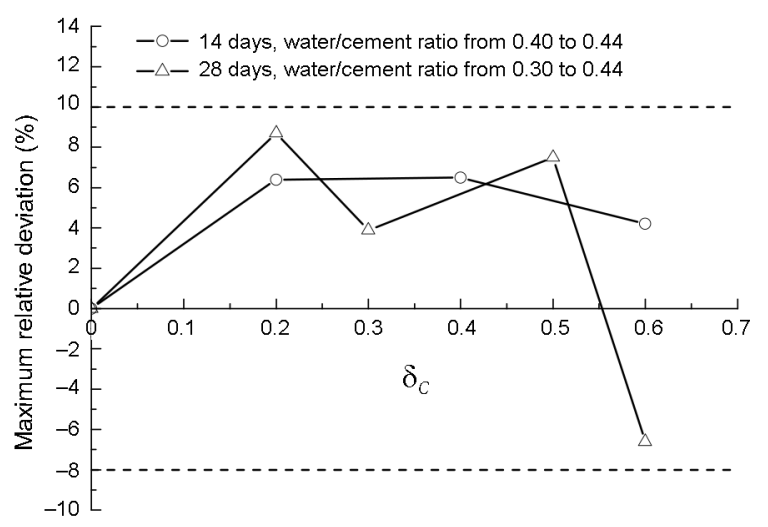

Figure 8. Influence of mix proportions of concrete on stress influence coefficient under compressive stress 
From the above, it can be seen that both the carbonation time and mix proportions of concrete have only minor effects on the stress influence coefficient. Therefore, the use of Eqn (4) for determining the stress influence coefficient is considered reasonable. It is noted that the adoption of novel materials in concrete production may affect the stress influence coefficient. Besides, it has been pointed out in Section 2 that the accelerated carbonation tests performed by the eleven researchers had the same environmental conditions. While this enabled direct comparison across the experimental data, the possible effects of environmental conditions including the ambient temperature and relative humidity on the stress influence coefficient could not be reflected in this paper. As a recommendation for further research, more experimental data and field measurements of carbonation depths are required to validate and refine the proposed equations under various materials and environmental conditions for improved accuracy and reliability.

\section{The modified carbonation depth model of concrete}

Substituting Eqn (4) into Eqn (3), the modified carbonation depth model which is suitable for concrete under tensile and compressive stress states can be obtained, as shown in Eqn (9) and Eqn (10), respectively:

Under tension:

$$
x_{\sigma}=\left(1.00+0.40 \delta_{T}+0.27 \delta_{T}^{2}\right) x_{0} .
$$

Under compression:

$$
x_{\sigma}=\left(1.00-0.30 \delta_{C}-0.16 \delta_{C}^{2}\right) x_{0} .
$$

In order to demonstrate the prediction accuracy of the modified carbonation depth model, the experimental data from Liu et al. (2004), Liu (2008b), Zheng and Huang (2013), and Xue (2016) are employed to verify Eqn (9) and Eqn (10), as depicted in Figures 9 to 14. The information about the tests of Liu et al. (2004), Liu (2008b), Zheng and

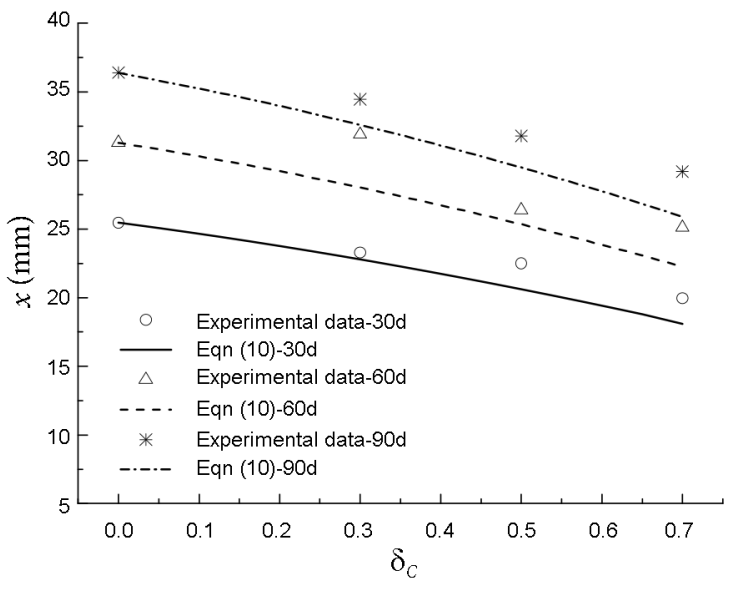

Figure 9. Comparison between the computed results from Eqn (10) and the experimental data from Liu et al. (2004)

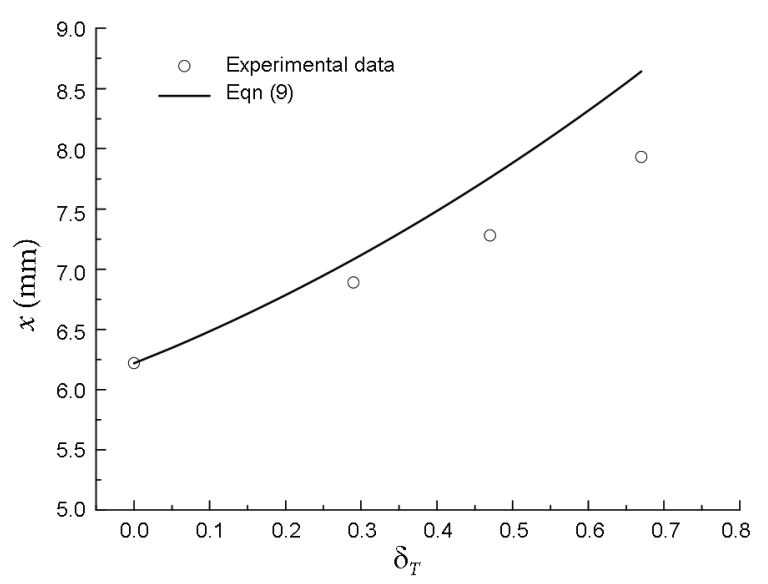

Figure 10. Comparison between the computed results from Eqn (9) and the experimental data from Liu (2008b)

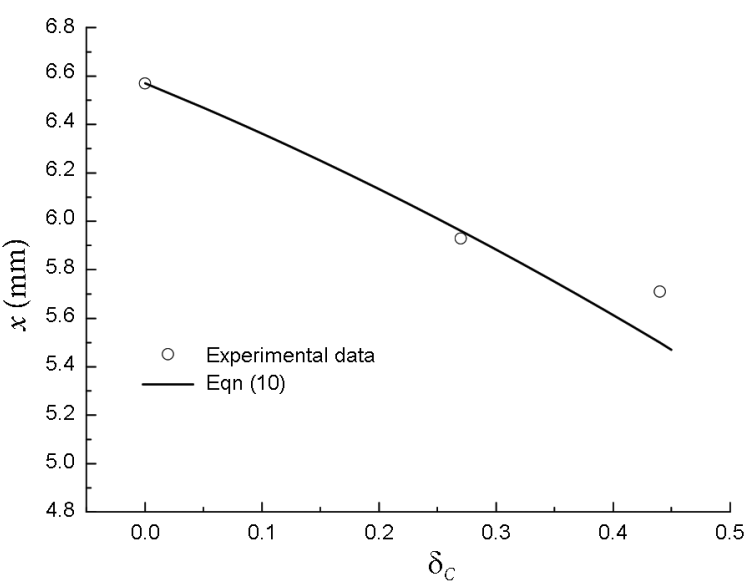

Figure 11. Comparison between the computed results from Eqn (10) and the experimental data from Liu (2008b)

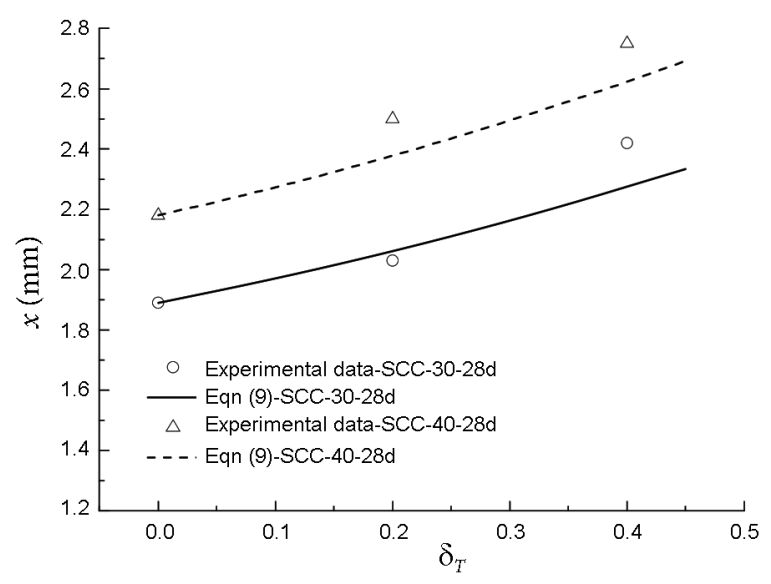

Figure 12. Comparison between the computed results from Eqn (9) and the experimental data from Zheng and Huang (2013) 


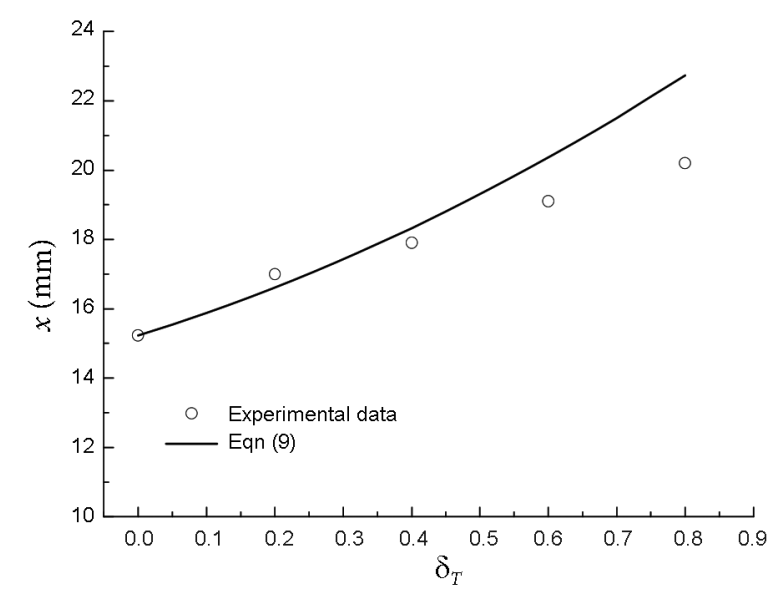

Figure 13. Comparison between the computed results from Eqn (9) and the experimental data from Xue (2016)

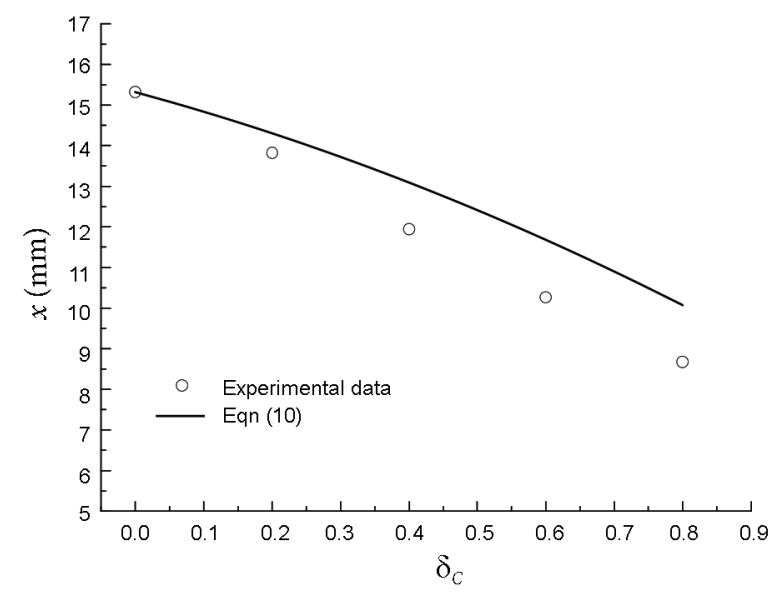

Figure 14. Comparison between the computed results from Eqn (10) and the experimental data from Xue (2016)

Huang (2013), and Xue (2016) has been introduced in Section 3 of this paper. From Figures 9 to 14, the root-meansquare error and maximum relative error of Eqn (9) are respectively $5.9 \%$ and $+11.2 \%$, and the root-mean-square error and maximum relative error of Eqn (10) are respectively $9.2 \%$ and $+13.9 \%$. Overall, the agreement between the modified carbonation depth models and the experimental data is good. This indicates that the proposed modified carbonation depth models are reliable for predicting the carbonation depth in concrete under stress states.

\section{Conclusions}

In this paper, the relationship between stress influence coefficient and concrete stress ratio has been investigated with reference to experimental data in the literature. From the quantitative analysis performed in this study, the following conclusions can be drawn:

1. The results indicate the relationships between the stress influence coefficient and concrete tensile stress ratio and concrete compressive stress ratio can be approximated by quadratic functions. The stress influence coefficient increases with increasing concrete tensile stress ratio, while it decreases with increasing concrete compressive stress ratio.

2. Compared with three typical existing groups of equations based on four groups of experimental data in the literature, it is found that the proposed equations of stress influence coefficient are more reasonable and have a higher reliability.

3. The research has shown that the provisions of stress influence coefficient given in CECS 220 (2007) are not sufficiently reasonable. Under concrete tensile stress, the stress influence coefficient is taken as a constant equal to 1.1, which gives rise to an error exceeding $15 \%$ (on the non-conservative side) when the tensile stress ratio is equal to 0.5 ; whereas under concrete compressive stress, the stress influence coefficient is taken as a constant equal to 1.0 , which gives rise to an error close to $20 \%$ (on the conservative side) when the compressive stress ratio is equal to 0.5 . The magnitude of errors increases with the stress ratios. It is advocated that the equations proposed from the present study can be adopted as the modified formula for stress influence coefficient in the concrete carbonation depth model.

4. The carbonation time and mix proportions of concrete have little effect on the stress influence coefficient and the magnitudes of the effects are approximately within $\pm 10 \%$.

5. The modified carbonation depth model is proposed and verified by the experimental data in the literature. The results have shown that the prediction accuracy of the proposed model is satisfactory.

6. It is recommended to conduct more experimental investigations and field measurements of concrete carbonation depths under various materials and environmental conditions to further validate and refine the proposed modified carbonation depth models, so as to improve the accuracy and reliability.

\section{Acknowledgements}

The authors would like to gratefully acknowledge the support from Ningbo Science and Technology Bureau of China (No. 2015C110020), Marie Skłodowska-Curie Actions of the European Commission (No. 751461), Science and technology project of Gansu Provincial Communications and Transportation Department of China (No. 201607), Foshan Science and Technology Project of China (No. 2016AB000031), Research Centre of Green Building Materials and Modular Integrated Construction Technology of Guangdong Province of China (No. ZCZX201803), and Jiangsu Provincial Transportation Engineering Construction Bureau of China (No. C18L01160) in carrying out this research. 


\section{Funding}

This work was supported by Ningbo Science and Technology Bureau of China under Grant No. 2015C110020; Marie Skłodowska-Curie Actions of the European Commission under Grant No. 751461; Science and technology project of Gansu Provincial Communications and Transportation Department of China under Grant No. 201607; Foshan Science and Technology Project of China under Grant No. 2016AB000031; Research Centre of Green Building Materials and Modular Integrated Construction Technology of Guangdong Province of China under Grant No. ZCZX201803; and Research project of Jiangsu Provincial Transportation Engineering Construction Bureau of China under Grant No. C18L01160.

\section{Author contributions}

JW and JD conceived the study. JW and HS conducted scientific research and performed data analysis. PN, HS and JC were responsible for data interpretation. JW and $\mathrm{PN}$ wrote the article.

\section{Disclosure statement}

The authors do not have any competing financial, professional, or personal interests from other parties.

\section{References}

Bary, B., \& Sellier, A. (2004). Coupled moisture-carbon dioxidecalcium transfer model for carbonation of concrete. Cement and Concrete Research, 34, 1859-1872.

https://doi.org/10.1016/j.cemconres.2004.01.025

Borges, P. H. R., Costa, J. O., Milestone, N. B., Lynsdale, C. J., \& Streatfield, R. E. (2010). Carbonation of CH and C-S-H in composite cement pastes containing high amounts of BFS. Cement and Concrete Research, 40(2), 284-292. https://doi.org/10.1016/j.cemconres.2009.10.020

Bouchaala, F., Payan, C., Garnier, V., \& Balayssac, J. P. (2011). Carbonation assessment in concrete by nonlinear ultrasound. Cement and Concrete Research, 41, 557-559. https://doi.org/10.1016/j.cemconres.2011.02.006

CECS 220. (2007). Standard for durability assessment of concrete structures. Beijing: China Architecture and Building Press.

Chang, C. F., \& Chen, J. W. (2006). The experimental investigation of concrete carbonation depth. Cement and Concrete Research, 36, 1760-1767. https://doi.org/10.1016/j.cemconres.2004.07.025

Chen, L. T. (2007). Research on concrete carbonation model and its parameters (Dissertation). Xi'an University of Architecture and Technology, China. https://doi.org/10.7666/d.d194716

GB/T 50082. (2009). Standard for test methods of long-term performance and durability of ordinary concrete. Beijing: China Architecture and Building Press.

Ghantous, R. M., Poyet, S., L'Hostis, V., Tran, N. C., \& François, R. (2017). Effect of crack openings on carbonation-induced corrosion. Cement and Concrete Research, 95, 257-269. https://doi.org/10.1016/j.cemconres.2017.02.014

Heiyantuduwa, R., Alexander, M. G., \& Mackechnie, J. R. (2006). Performance of a penetrating corrosion inhibitor in concrete affected by carbonation-induced corrosion. Journal of Materials in Civil Engineering, 18(6), 842-850.

https://doi.org/10.1061/(ASCE)0899-1561(2006)18:6(842)

Hills, T. P., Gordon, F., Florin, N. H., \& Fennell, P. S. (2015). Statistical analysis of the carbonation rate of concrete. Cement and Concrete Research, 72, 98-107.

https://doi.org/10.1016/j.cemconres.2015.02.007

Huang, T. (2013). Experimental study on the interrelation of concrete carbonation and chloride corrosion under load (Dissertation). Zhejiang University, China.

Ishida, T., \& Li, C. H. (2008). Modeling of carbonation based on thermo-hygro physics with strong coupling of mass transport and equilibrium in micro-pore structure of concrete. Journal of Advanced Concrete Technology, 6(2), 303-316. https://doi.org/10.3151/jact.6.303

Jiang, C., Gu, X. L., Zhang, W. P., \& Zou, W. (2015). Modeling of carbonation in tensile zone of plain concrete beams damaged by cyclic loading. Construction and Building Materials, 77, 479-488. https://doi.org/10.1016/j.conbuildmat.2014.12.088

Jin, L., Zhang, R. B., Du, X. L., \& Li, Y. (2015). Multi-scale analytical theory of the diffusivity of concrete subjected to mechanical stress. Construction and Building Materials, 95, 171-185. https://doi.org/10.1016/j.conbuildmat.2015.07.123

Kari, O. P., Puttonen, J., \& Skantz, E. (2014). Reactive transport modelling of long-term carbonation. Cement and Concrete Composites, 52(8), 42-53. https://doi.org/10.1016/j.cemconcomp.2014.05.003

Khunthongkeaw, J., Tangtermsirikul, S., \& Leelawat, T. (2006). A study on carbonation depth prediction for fly ash concrete. Construction and Building Materials, 20(9), 744-753. https://doi.org/10.1016/j.conbuildmat.2005.01.052

Kobayashi, K., Suzuki, K., \& Uno, Y. (1994). Carbonation of concrete structures and decomposition of C-S-H. Cement and Concrete Research, 24(1), 55-61. https://doi.org/10.1016/0008-8846(94)90082-5

Li, D., Chen, B., Sun, H., Memon, S. A., Deng, X., Wang, Y., \& Xing, F. (2018). Evaluating the effect of external and internal factors on carbonation of existing concrete building structures. Construction and Building Materials, 167, 73-81. https://doi.org/10.1016/j.conbuildmat.2018.01.127

Li, G., Dong, L., Bai, Z., Lei, M., \& Du, J. M. (2017a). Predicting carbonation depth for concrete with organic film coatings combined with ageing effects. Construction and Building Materials, 142, 59-65. https://doi.org/10.1016/j.conbuildmat.2017.03.063

Li, Y., Du, D., Liu, W., \& Zhang, L. (2017b). Experimental and numerical investigation of carbonation mechanism for concrete with blended admixtures under load. Concrete, 10, 1519. https://doi.org/10.3969/j.issn.1002-3550.2017.10.005

Liu, J. (2008b). Durability test of prestressed concrete members (Dissertation). Tongji University, China.

Liu, R. G., Lu, C. H., Lei, L. H., \& Lv, Z. T. (2004). Study on durability of modern prestressed concrete structure in carbonation. Industrial Construction, 34(4), 69-72. https://doi.org/10.13204/j.gyjz2004.04.020

Liu, W. L. (2008a). Research on carbonation rule of fly ash concrete under bending loading and environment (Dissertation). Xi'an University of Architecture and Technology, China. https://doi.org/10.7666/d.d195966

Liu, Y. Q. (1997). Practical calculation model of reinforced bar corrosion caused by concrete carbonation (Dissertation). Tongji University, China.

Neves, R., Branco, F., \& Brito, J. D. (2013). Field assessment of the relationship between natural and accelerated concrete car- 
bonation resistance. Cement and Concrete Composites, 41(4), 9-15. https://doi.org/10.1016/j.cemconcomp.2013.04.006

Nguyen, T. T. H., Bary, B., \& Larrard, T. D. (2015). Coupled carbonation-rust formation-damage modeling and simulation of steel corrosion in 3D mesoscale reinforced concrete. Cement and Concrete Research, 74, 95-107.

https://doi.org/10.1016/j.cemconres.2015.04.008

Niu, D. T. (2003). Durability and life forecast of reinforced concrete structure. Beijing: Science Press.

Pan, H. K. (2005). Durability and reliability of underground engineering structures based on concrete carbonation (Dissertation). Tongji University, China. https://doi.org/10.7666/d.y846763

Papadakis, V. G., Vayenas, C. G., \& Fardis, M. N. (1989). A reaction engineering approach to the problem of concrete carbonation. AIChE Journal, 35(10), 1639-1650. https://doi.org/10.1002/aic.690351008

Papadakis, V. G., Vayenas, C. G., \& Fardis, M. N. (1991a). Fundamental modeling and experimental investigation of concrete carbonation. ACI Materials Journal, 88(4), 363-373. https://doi.org/10.14359/1863

Papadakis, V. G., Vayenas, C. G., \& Fardis, M. N. (1991b). Physical and chemical characteristics affecting the durability of concrete. ACI Materials Journal, 88(2), 186-196.

Paul, S. C., Panda, B., Huang, Y., Garg, A., \& Peng, X. (2018). An empirical model design for evaluation and estimation of carbonation depth in concrete. Measurement, 124, 205-210. https://doi.org/10.1016/j.measurement.2018.04.033

Possan, E., Thomaz, W. A., Aleandri, G. A., Felix, E. F., \& Santos, A. C. P. (2017). $\mathrm{CO}_{2}$ uptake potential due to concrete carbonation: A case study. Case Studies in Construction Materials, 6, 147-161. https://doi.org/10.1016/j.cscm.2017.01.007

Ruan, X., \& Pan, Z. C. (2012). Mesoscopic simulation method of concrete carbonation process. Structure and Infrastructure Engineering, 8(2), 99-110. https://doi.org/10.1080/15732479.2011.605370

Shi, Q. L. (2008). Experimental study on carbonation durability of concrete under stress state (Dissertation). Central South University, China. https://doi.org/10.7666/d.y1324263

Shui, Z. H., Yu, R., Chen, Y. X., Duan, P., Ma, J. T., \& Wang, X. P. (2018). Improvement of concrete carbonation resistance based on a structure modified layered double hydroxides (LDHs): Experiments and mechanism analysis. Construction and Building Materials, 176, 228-240. https://doi.org/10.1016/j.conbuildmat.2018.04.222

Steffens, A., Dinkler, D., \& Ahrens, H. (2002). Modeling carbonation for corrosion risk prediction of concrete structures. Cement and Concrete Research, 32(6), 935-941.

https://doi.org/10.1016/S0008-8846(02)00728-7

Tang, J., Wu, J., Zou, Z., Yue, A., \& Mueller, A. (2018). Influence of axial loading and carbonation age on the carbonation resistance of recycled aggregate concrete. Construction and Building Materials, 173, 707-717. https://doi.org/10.1016/j.conbuildmat.2018.03.269

Tu, Y. M. (2002). Research on the mechanism of the durability of modern prestressed concrete structures (Dissertation). Southeast University, China.

Wang, J., Ng, P. L., Su, H., \& Du, J. S. (2019). Meso-scale modelling of stress effect on chloride diffusion in concrete using three-phase composite sphere model. Materials and Structures, 52(3), 1-23. https://doi.org/10.1617/s11527-019-1355-8

Wang, J., Su, H., \& Du, J. (2018). Influence of coupled effects between flexural tensile stress and carbonation time on the carbonation depth of concrete. Construction and Building Materials, 190, 439-451. https://doi.org/10.1016/j.conbuildmat.2018.09.117

Wang, M. (2012). Carbonation and chloride ion erosion test and theoretical analysis of steamed prestressed concrete (Dissertation). Central South University, China. https://doi.org/10.7666/d.y2197234

Wang, W., Lu, C., Li, Y., Yuan, G., \& Li, Q. (2017). Effects of stress and high temperature on the carbonation resistance of fly ash concrete. Construction and Building Materials, 138, 486-495. https://doi.org/10.1016/j.conbuildmat.2017.02.039

Wang, Y. B. (2018). Research on carbonization of concrete box girder under bending load (Dissertation). Lanzhou Jiaotong University, China.

Wu, Y. X. (2009). Test of carbonation and chloride ion erosion of prestressed concrete members (Dissertation). Tongji University, China.

Xu, J., \& Li, F. M. (2017). A meso-scale model for analyzing the chloride diffusion of concrete subjected to external stress. Construction and Building Materials, 130, 11-21. https://doi.org/10.1016/j.conbuildmat.2016.11.054

Xue, L. (2016). Study on concrete carbonation under different stress states. Highways and Transportation in Inner Mongolia, 5, 32-34. https://doi.org/10.19332/j.cnki.10050574.2016.05.009

Yang, L. D., Pan, H. K., Zhu, Y. Z., \& Wu, Z. Z. (2008). Experimental study of concrete's carbonation resistance under combined action of factors. Journal of Building Materials, 11(3), 345-348. https://doi.org/10.3969/j.issn.1007-9629.2008.03.017

Zhang, D. F. (2001). Research on the durability of modern prestressed concrete structures (Dissertation). Southeast University, China.

Zhang, P., Wang, S., Han, J., \& Liu, W. (2017). Carbonation resistance and microstructure evolution of concrete under static load test. Concrete, 10, 45-51. https://doi.org/10.3969/j.issn.1002-3550.2017.10.012

Zhang, Y. S., Sun, W., Chen, S., Guo, F., \& Zhao, Q. (2007). 1D and $2 \mathrm{D}$ carbonation of fly ash concrete under flexural stress. Journal of Southeast University (Natural Science Edition), $37(1), 118-122$. https://doi.org/10.3321/j.issn:1001-0505.2007.01.025

Zheng, J. L., \& Huang, L. P. (2013). Experimental study on carbonation of self-compacting concrete under tensile and compressive stresses. Journal of Building Materials, 16(1), 115-120. https://doi.org/10.3969/j.issn.1007-9629.2013.01.022

Zhou, S. B. (2011). Study on experiment for the influence of environmental factors and bending load on anti-corrosion performance of concrete (Dissertation). Zhejiang University of Technology, China. https://doi.org/10.7666/d.y2068743

Zhou, Y., Gencturk, B., Willam, K., \& Attar, A. (2015). Carbonation-induced and chloride-induced corrosion in reinforced concrete structures. Journal of Materials in Civil Engineering, 27(9), 04014245.

https://doi.org/10.1061/(ASCE)MT.1943-5533.0001209 